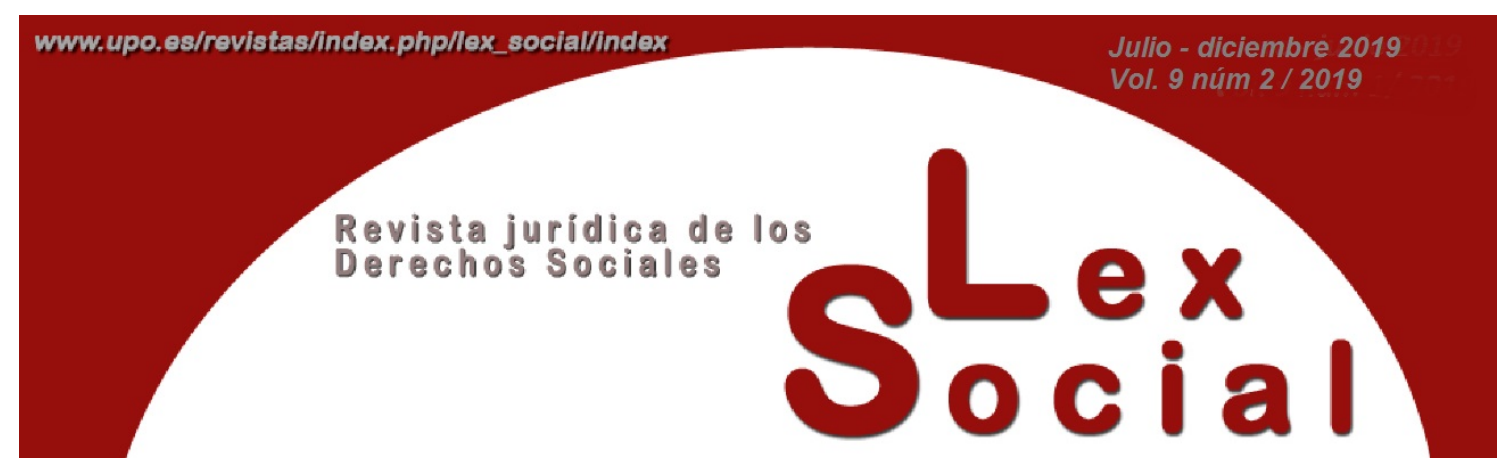

\title{
EL PAPEL DE LA INSPECCIÓN DE TRABAJO Y SEGURIDAD SOCIAL EN EL CONTROL DEL CUMPLIMIENTO DE LA NORMATIVA APLICABLE
}

\author{
THE ROLE OF THE LABOUR AND SOCIAL SECURITY \\ INSPECTORATE IN THE CONTROL OF COMPLIANCE WITH THE \\ APPLICABLE LEGISLATION
}

CRISTINA FERNÁNDEZ GONZÁLEZ Inspectora de Trabajo y Seguridad Social

Artículo recibido el 10 de mayo de 2019

Artículo aceptado el 27 de mayo de 2019

\section{RESUMEN}

La Inspección de Trabajo y Seguridad Social tiene como misión la vigilancia y exigencia del cumplimiento de la normativa vigente en el orden social, también la normativa reguladora de la relación laboral del servicio del hogar familiar, así como las normas relativas al sistema especial de la seguridad social de los empleados de hogar, convirtiéndose así en instrumento garante de su eficacia normativa.

El artículo pretende analizar las peculiaridades de la actuación inspectora en estas relaciones y las conductas que pueden ser constitutivas de infracción en todas las dimensiones de la actuación inspectora.

Palabras Clave: inspección de trabajo y seguridad social, ámbito de actuación, infracciones y sanciones. 


\begin{abstract}
The labour and social security inspectorate has as its mission the monitoring and demand of compliance with the current labour regulations, also the rules regulating the relationship of familiy home service as well as the rules relating to the special system of social security of home employees, becoming an instrument guarantee of its effectiveness.

The article intends to analyze the peculiarities of the inspecting actions in these relationships and the behaviors that may be constitutive of infringiment in all dimensions of the inspecting action.
\end{abstract}

KEYWORDS: Labour and social security inspectorate, scope of action, infringements and sanctions.

SUMARIO

1. INTRODUCCIÓN

2. ACTUACIÓN DE LA INSPECCIÓN DE TRABAJO Y SEGURIDAD SOCIAL EN EL HOGAR FAMILIAR

2.1. VISITA

2.2. OTRAS FORMAS DE ACTUACIÓN

3. INICIO DE LA ACTUACIÓN INSPECTORA

3.1. DENUNCIA

3.2. PLANES Y PROGRAMAS DE ACTUACIÓN

3.3. A PETICIÓN RAZONADA DE OTROS ÓRGANOS

4. ÁMBITO DE ACTUACIÓN

4.1. SISTEMA DE RELACIONES LABORALES

4.2. PREVENCIÓN DE RIESGOS LABORALES

4.3. SISTEMA DE SEGURIDAD SOCIAL

4.3.1. ENCUADRAMIENTO Y COTIZACIÓN

4.3.2. FRAUDE EN ACCESO A PRESTACIONES

4.4. TRABAJO DE EXTRANJEROS 


\section{INTRODUCCIÓN}

Las normas laborales de derecho positivo sólo son eficaces en la medida en que se prevén mecanismos que garantizan su efectivo cumplimiento. Esta misión está encomendada a la Inspección de Trabajo y Seguridad Social, sistema al que corresponde la vigilancia y exigencia del cumplimiento de la normativa laboral y de Seguridad Social, también la que regula la relación laboral especial de empleados de hogar y su protección en el Sistema de Seguridad Social.

Según establece el artículo 1.1. de la Ley 23/2015, de 21 de julio, Ordenadora del Sistema de Inspección de Trabajo y Seguridad Social (BOE 22/07/2015), dicho sistema está constituido por el conjunto de principios legales, normas, órganos, personal y medios materiales, incluidos los informáticos, que contribuyen al adecuado cumplimiento de la misión que tiene encomendada

Esta misión se recoge en el apartado 2 del citado artículo 1 que señala que "la Inspección de Trabajo y Seguridad Social es un servicio público al que corresponde ejercer la vigilancia del cumplimiento de las normas del orden social y exigir las responsabilidades pertinentes, así como el asesoramiento y, en su caso, conciliación, mediación y arbitraje en dichas materias, lo que efectuará de conformidad con los principios del Estado social y democrático de Derecho que consagra la Constitución Española, y con los Convenios número 81 y 129 de la Organización Internacional del Trabajo.”

La actuación de la Inspección de Trabajo y Seguridad Social en el ámbito del trabajo doméstico presenta peculiaridades derivadas de dos circunstancias.

De un lado, el empleador no es un empresario que desarrolla una actividad empresarial con carácter lucrativo, sino el titular del hogar familiar que necesita la colaboración del empleado para la realización de tareas domésticas.

Por otro lado, el lugar de prestación de servicios no es un centro de trabajo ordinario sino un domicilio particular, protegido por del derecho a la intimidad de su legítimo titular.

\section{ACTUACIÓN DE LA INSPECCIÓN DE TRABAJO Y SEGURIDAD SOCIAL EN EL HOGAR FAMILIAR}

\subsection{Visita}

El artículo 19 de la Ley 23/2015, de 21 de julio, Ordenadora del Sistema de Inspección de Trabajo y Seguridad Social (BOE 22/07/2015) relativo al ámbito de actuación de la Inspección de Trabajo señala que la actuación de la Inspección de Trabajo y Seguridad Social se extiende a las personas físicas y jurídicas, públicas o privadas, a las comunidades de bienes u otras entidades sin personalidad jurídica, en cuanto sujetos obligados o responsables que sean del cumplimiento de las normas del orden social. 
Por tanto, en la medida que los titulares del hogar familiar son sujetos responsables del cumplimiento de obligaciones establecidas en la normativa reguladora de la relación laboral de empleados de hogar y en materia de Seguridad Social quedan dentro del ámbito de actuación de la Inspección de Trabajo y en su calidad de empleadores son posibles sujetos responsables de las infracciones tipificadas en el Texto Refundido de la Ley General de la Seguridad Social, aprobado por Real Decreto Legislativo 5/2000, de 4 de agosto (BOE 08/08/2000) (TRLISOS)

Continúa el artículo 19 señalando que la actuación inspectora se ejercerá en las empresas, los centros de trabajo y, en general, los lugares en que se ejecute la prestación laboral. Así, en la medida en que la prestación laboral de los empleados de hogar se lleva a cabo en el domicilio del empleador éste se convierte en lugar sujeto a inspección.

Tanto el artículo 13 de la Ley Ordenadora del Sistema de Inspección de Trabajo y Seguridad Social, como el artículo 7 del Real Decreto 138/2000, de 4 de febrero, que aprueba el Reglamento de Organización y Funcionamiento de la Inspección de Trabajo y Seguridad Social (BOE 16/02/2000) recogen entre las facultades de los Inspectores de Trabajo y Seguridad Social para el ejercicio de su función, la de entrar libremente en cualquier momento y sin previo aviso en todo centro de trabajo, establecimiento o lugar sujeto a inspección y a permanecer en el mismo. Si el centro sometido a inspección coincidiese con el domicilio de una persona física, deberán obtener su expreso consentimiento o, en su defecto, la oportuna autorización judicial.

Por tanto, la única limitación a la facultad de entrar y permanecer en los centros de trabajo o lugares sujetos a inspección que tienen reconocida los Inspectores de Trabajo y Seguridad Social y Subinspectores Laborales en el ejercicio de sus funciones, es la entrada al domicilio de una persona física. Esta circunstancia, por definición se producirá siempre en las actuaciones de vigilancia y control ejercidas en torno a la relación laboral del servicio del hogar familiar, por lo que en estos casos, la actuación mediante visita al centro de trabajo, hogar familiar, requerirá el expreso consentimiento de su titular o bien autorización judicial.

Con respecto a la autorización judicial, el artículo 76.5 de la Ley 37/2011, de 10 de octubre, reguladora de la Jurisdicción Social (BOE 11/10/2011) (LRJS) establece que "La Inspección de Trabajo y Seguridad Social y, en su caso, la Administración laboral, en el ejercicio de sus funciones, cuando el centro de trabajo sometido a inspección coincidiese con el domicilio de la persona afectada, podrá solicitar la correspondiente autorización judicial, si el titular se opusiere o existiese riesgo de tal oposición, en relación con los procedimientos administrativos de los que conozca o pueda conocer posteriormente la jurisdicción social, o para posibilitar cualquier otra medida de inspección o control que pudiera afectar a derechos fundamentales o libertades públicas.” 
La solicitud de autorización judicial en al ámbito de la jurisdicción social requeriría, por un lado, que el titular se opusiere o existiese riesgo de tal oposición, por lo que parece que resultaría necesario un intento previo de actuación que ponga de manifiesto la oposición o actitud obstruccionista del empleador y que justifique la solicitud. De esta forma, aunque finalmente sea posible el acceso al domicilio, se habrá perdido la inmediatez y el carácter sorpresivo que esta facultad de entrada y permanencia tiene de cara a la eficacia de la actuación.

Por otro lado, la intervención de la jurisdicción social está prevista para procedimientos administrativos que conozca o pueda conocer este orden jurisdiccional. Sin embargo, gran parte de las actuaciones realizadas por la Inspección de Trabajo y Seguridad Social en este ámbito, como es el control del encuadramiento y cotización en el Sistema de Seguridad Social son revisables por la jurisdicción contencioso administrativa, por lo que quedarían fuera de la previsión del artículo 76.5 de la LRJS.

El artículo 8.6 de la Ley 29/1998, de 13 de julio, de la Jurisdicción Contencioso Administrativa (BOE 14/07/1998) señala que “conocerán también los Juzgados de lo Contencioso-administrativo de las autorizaciones para la entrada en domicilios y restantes lugares cuyo acceso requiera el consentimiento de su titular, siempre que ello proceda para la ejecución forzosa de actos de la administración pública, salvo que se trate de la ejecución de medidas de protección de menores acordadas por la Entidad Pública competente en la materia.”

Si bien el citado precepto permite obtener autorización judicial para la entrada en domicilios particulares cuando proceda para la ejecución forzosa de actos de la administración pública, la Sentencia del Tribunal Constitucional 50/1995, de 23 de febrero (La Ley 13050/1995), referente a un Auto en que se autorizaba a la Inspección de Tributos para entrar en domicilio, amplía esa posibilidad al ejercicio de la función investigadora de la Inspección de Hacienda. Así señala que “Tanto o más razón existe para que se extienda el ámbito de la norma, por vía analógica ante el silencio de la Ley al procedimiento de la Inspección Tributaria, con una semejanza tan notable con la instrucción sumarial en los aspectos que tocan al casi inevitable desencadenamiento de la potestad sancionadora o del tanto de culpa a la propia jurisdicción penal. La operación en que consiste tal extensión de la norma a supuesto no previstos en ella se produce en el plano de la legalidad ordinaria, privativo de la potestad de juzgar que encomienda la Constitución a los Jueces y Tribunales del Poder Judicial, sin que le alcance reproche alguno en el nivel de la constitucionalidad, desde el momento en que éste defiere a aquella la delimitación de los límites de la inviolabilidad del domicilio. Se cumple así, por otra parte, la exigencia de que sea siempre un Juez, por su independencia e imparcialidad, quien adopte estas medidas.”

La actuación de la Inspección de Trabajo y Seguridad Social en el ámbito de las relaciones laborales del hogar familiar está así claramente condicionada por la inviolabilidad del domicilio en el que se desarrolla la prestación de servicios y que 
limita la principal facultad otorgada a los funcionarios del sistema para el ejercicio de su labor de vigilancia, que es la de entrada y permanencia en los centros de trabajo. De no obtenerse el consentimiento expreso del titular del hogar familiar para acceder al mismo, resulta complicado realizar la actuación inspectora mediante visita al lugar de trabajo.

\subsection{Otras formas de actuación}

Otras formas de actuación permiten llevar a cabo la vigilancia y control del cumplimento de la normativa que tiene encomendada la Inspección de Trabajo y Seguridad Social. El artículo 21 de la Ley Ordenadora del Sistema de Inspección de Trabajo y Seguridad Social establece la posibilidad de actuación mediante requerimiento de comparecencia ante el funcionario actuante de quien resulte obligado, aportando la documentación que se señale.

El artículo 15 del Real Decreto 138/2000, de 4 de febrero, de Organización y Funcionamiento de la Inspección de Trabajo y Seguridad Social (BOE 16/02/2000) (ROFIT) desarrolla este precepto señalando que la actuación se puede llevar a cabo mediante comparecencia de los sujetos obligados ante el funcionario actuante en la oficina pública que éste señale, en virtud de requerimiento, con o sin aportación de información documental o mediante la comprobación de datos o antecedentes que obren en las Administraciones públicas; a tal fin, la Inspección podrá acceder a tales datos y antecedentes, proceder a cruces informáticos y solicitar antecedentes o información que permita comprobar el cumplimiento de la normativa aplicable.

Así, por ejemplo, la Inspección de Trabajo puede acceder a datos obrantes en otras administraciones con objeto de conocer el alta y cotización del trabajador en el Sistema de Seguridad Social, la posible percepción de prestaciones incompatibles con el trabajo por cuenta ajena o si el trabajador extranjero dispone de autorización de residencia y/o trabajo.

También las obligaciones de colaboración y auxilio previstas en el artículo 18 de la citada Ley 23/2015 facilitan la labor inspectora. Así toda persona natural o jurídica estará obligada a proporcionar a la Inspección de Trabajo y Seguridad Social toda clase de datos, antecedentes o información con trascendencia en los cometidos inspectores, siempre que se deduzcan de sus relaciones económicas, profesionales, empresariales o financieras con terceros sujetos a la acción inspectora, cuando a ello sea requerida en forma.

No obstante, las personas que podrían facilitar información con trascendencia en la actuación inspectora en el ámbito del hogar familiar difícilmente van a estar vinculadas el titular del hogar familiar o al trabajador como consecuencia de relaciones económicas, profesionales, empresariales o financieras, sino más bien, por relaciones personales, que no quedan amparadas por esta obligación de colaboración y auxilio, debido a que la relación discurre en un entorno íntimo y personal. 
Si estarían vinculadas por esta obligación de colaboración y suministro de información las entidades colaboradoras de los órganos de recaudación de la Seguridad Social y las depositarias de dinero en efectivo o de fondos en cuanto a la identificación de pagos realizados con cargo a las cuentas que pueda tener en dicha entidad la persona que se señale en el correspondiente requerimiento, sin que puedan ampararse en el secreto bancario.

\section{INICIO DE LA ACTUACIÓN INSPECTORA}

De conformidad con lo previsto en el artículo 20 de la Ley 23/2015, de 21 de julio, Ordenadora del Sistema de Inspección de Trabajo y Seguridad Social (BOE 22/07/2015) ésta actuará de oficio siempre, como consecuencia de orden superior, de orden de servicio derivada de planes o programas de inspección, a petición razonada de otros órganos, en virtud de denuncia o por propia iniciativa de los Inspectores de Trabajo y Seguridad Social.

La propia iniciativa está facultada sólo para los funcionarios del Cuerpo Superior de Inspectores de Trabajo y Seguridad Social, la tienen vedada los funcionarios del Cuerpo de Subinspectores Laborales y tiene poca repercusión en actuaciones en el ámbito del hogar familiar.

Las principales formas de inicio de actuación inspectora serán por tanto el cumplimiento de planes y programas de actuación y la denuncia.

\subsection{Denuncia}

La principal forma de inicio de actuación inspectora es la denuncia, que según señala el apartado 4 del artículo 20 de la Ley Ordenadora es pública. Cualquier persona puede presentarla con la única de limitación de que no sean anónimas, coincidan con asuntos de los que esté conociendo un órgano jurisdiccional o manifiestamente carezcan de fundamento. La Inspección tiene obligación de guardar sigilo sobre el origen de sus actuaciones.

No obstante, caben denuncias anónimas presentadas a través del buzón de la Inspección de Trabajo y Seguridad Social. El Plan Director por un Trabajo Digno 2018-2019-2020 (BOE 28-7-2018) incluye como una de sus medidas operativas, la creación este buzón, cuya finalidad es reorientar el anterior Buzón de Lucha contra el Fraude Laboral, puesto en marcha en agosto de 2013, de manera que ahora se reflejen en él todos los comportamientos que implican precarización laboral en el empleo.

\subsection{Planes y programas de actuación}

Si se examinan los planes de actuación publicados en la página web de la Inspección de Trabajo y Seguridad Social se constata que se programan actuaciones en materia de economía irregular por sectores, incluyéndose el hogar como uno de estos sectores. Estas actuaciones están dirigidas al afloramiento de relaciones laborales ocultas y tienen 
por objeto vigilar el cumplimiento de las obligaciones de alta en el Sistema de Seguridad Social.

No obstante, al desarrollarse la prestación en un domicilio particular, la planificación de actuaciones en este ámbito resulta problemático ante la ausencia de fuentes para la localización de lugares donde se pueda estar desarrollando la prestación de forma opaca. En cualquier caso, resulta posible una cierta actuación planificada utilizando la información facilitada a través del buzón de la inspección de trabajo antes referido.

Así lo señala la propia página web del Ministerio de Trabajo, Migraciones y Seguridad Social: "La Inspección de Trabajo y S.S. en el ejercicio de sus funciones, planifica sus actuaciones con el objetivo de conseguir el cumplimiento de la normativa laboral y evitar en lo posible las irregularidades. No obstante para una mejor identificación de las mismas, el Ministerio de Trabajo, Migraciones y Seguridad Social, a través del Organismo Estatal de la Inspección de Trabajo y Seguridad Social, pone a disposición de todos los ciudadanos el "BUZÓN LA INSPECCIÓN DE TRABAJO Y SEGURIDAD SOCIAL" donde todo aquel conocedor de algún incumplimiento de la normativa ya sea laboral, incluidos supuestos de discriminación, de Seguridad Social o de Prevención de Riesgos Laborales, puede ponerlo en conocimiento de la Inspección de Trabajo y Seguridad Social (ITSS) (...)”

\subsection{A petición razonada de otros órganos}

La actuación inspectora puede también iniciarse a petición razonada de otros órganos, sobre todo entidades gestoras de prestaciones (INSS y SPEE) que llevan a cabo solicitudes de actuación en casos en que adviertan indicios de fraude en acceso a prestaciones fruto de relaciones en el ámbito del trabajo en el hogar familiar.

\section{4.ÁMBITO DE ACTUACION.}

El artículo 12 de la Ley 23/2015, de 21 de julio, Ordenadora del Sistema de Inspección de Trabajo y Seguridad Social (BOE 22/07/2015) señala que la función inspectora comprende como principal cometido la vigilancia y exigencia del cumplimiento de las normas legales, reglamentarias y del contenido de los acuerdos y convenios colectivos, en los siguientes ámbitos:
a) Sistema de relaciones laborales.
b) Prevención de riesgos laborales.
c) Sistema de la Seguridad Social.
d) Empleo.
e) Migraciones. 


\subsection{Sistema de relaciones laborales}

El Real Decreto 1620/2011, de 14 de noviembre, por el que se regula la relación laboral de carácter especial del servicio del hogar familiar (BOE 17/11/2011) establece en su artículo 3 referido a las fuentes de la relación laboral que "Los derechos y obligaciones concernientes a esta relación laboral de carácter especial se regularán:

a) Por las disposiciones de este real decreto.

b) Con carácter supletorio, en lo que resulte compatible con las peculiaridades derivadas del carácter especial de esta relación, será de aplicación la normativa laboral común. Expresamente no será de aplicación el artículo 33 del Estatuto de los Trabajadores.

c) Por los convenios colectivos.

d) Por la voluntad de las partes manifestada en el contrato de trabajo, que habrá de respetar lo establecido en las disposiciones legales y en los convenios colectivos.

e) Por los usos y costumbres locales y profesionales."

Teniendo en cuenta que no hay convenio colectivo aplicable a estas relaciones de trabajo y que el cumplimiento del contrato de trabajo será exigible ante los tribunales del orden jurisdiccional social, corresponde a la Inspección de Trabajo vigilar el cumplimiento de las normas recogidas en el citado Real Decreto 1620/2011 y las disposiciones recogidas en el Texto Refundido del Estatuto de los Trabajadores aprobado por Real Decreto Legislativo 2/2015, de 23 de octubre y que se aplican con carácter supletorio.

En materia de relaciones laborales el Real Decreto 1620/2011 recoge normas sobre la forma del contrato de trabajo (artículo 5), duración del contrato y período de prueba (artículo 6), retribuciones (artículo 8), tiempo de trabajo (artículo 9).

El artículo 12 atribuye expresamente a la Inspección de Trabajo y Seguridad Social el control del cumplimiento de la legislación laboral.

En la medida en que los incumplimientos de la norma estén tipificados como infracción administrativa en el Real Decreto Legislativo 5/2000, de 4 de agosto, por el que se aprueba el Texto Refundido de la Ley de Infracciones y Sanciones en el Orden Social (BOE 08/08/2000) (TRLISOS) los Inspectores de Trabajo y Seguridad Social o los Subinspectores Laborales de empleo y seguridad social podrán adoptar alguna de las siguientes medidas previstas en el artículo 22 de la Ley Ordenadora del sistema de la Inspección de Trabajo y Seguridad Social: 
- Advertir y requerir al sujeto responsable, en vez de iniciar un procedimiento sancionador, cuando las circunstancias del caso así lo aconsejen, y siempre que no se deriven perjuicios directos a los trabajadores o a sus representantes.

- Iniciar el procedimiento sancionador mediante la extensión de actas de infracción o de infracción por obstrucción.

El artículo 5 del TRLISOS define las infracciones laborales como las acciones u omisiones de los empresarios contrarias a las normas legales, reglamentarias y cláusulas normativas de los convenios colectivos en materia de relaciones laborales.

Las infracciones laborales que pueden producirse en el ámbito de la relación laboral de empleados de hogar serían las siguientes:

Infracciones leves previstas en el artículo 6 del TRLISOS:

- No entregar puntualmente al trabajador el recibo de salarios o no utilizar el modelo de recibo de salarios aplicable, oficial o pactado.

- No informar por escrito al trabajador sobre los elementos esenciales del contrato y las principales condiciones de ejecución de la prestación laboral, en los términos y plazos establecidos reglamentariamente.

- Cualesquiera otros incumplimientos que afecten a obligaciones meramente formales o documentales

Infracciones graves previstas en el art. 7 TRLISOS:

- No formalizar por escrito el contrato de trabajo cuando este requisito sea exigible o cuando lo haya solicitado el trabajador.

- La transgresión de la normativa sobre modalidades contractuales, contratos de duración determinada y temporales, mediante su utilización en fraude de ley o respecto a personas, finalidades, supuestos y límites temporales distintos de los previstos legal, reglamentariamente, o mediante convenio colectivo cuando dichos extremos puedan ser determinados por la negociación colectiva.

- No consignar en el recibo de salarios las cantidades realmente abonadas al trabajador.

- El incumplimiento de las obligaciones establecidas en materia de tramitación de los recibos de finiquito.

- La transgresión de las normas y los límites legales o pactados en materia de jornada, trabajo nocturno, horas extraordinarias, horas complementarias, descansos, vacaciones, permisos, registro de jornada y, en general, el tiempo de trabajo a que se refieren los artículos 12, 23 y 34 a 38 del Estatuto de los Trabajadores. 
- La modificación de las condiciones sustanciales de trabajo impuesta unilateralmente por el empresario, sin acudir a los procedimientos establecidos en el artículo 41.

- Establecer condiciones de trabajo inferiores a las establecidas legalmente o por convenio colectivo, así como los actos u omisiones que fueren contrarios a los derechos de los trabajadores reconocidos en el artículo 4 de la Ley del Estatuto de los Trabajadores.

Infracciones muy graves previstas en el artículo 8 del TRLISOS:

- El impago y los retrasos reiterados en el pago del salario debido.

- La transgresión de las normas sobre trabajo de menores contempladas en la legislación laboral.

- Los actos del empresario que fueren contrarios al respeto de la intimidad y consideración debida a la dignidad de los trabajadores.

- El acoso sexual, cuando se produzca dentro del ámbito a que alcanzan las facultades de dirección empresarial, cualquiera que sea el sujeto activo de la misma.

Las cuantías de las sanciones por estos incumplimientos se recogen en el artículo 40 del Texto Refundido de la Ley de Infracciones y Sanciones en el Orden social:

Las leves se sancionarán en su grado mínimo, con multas de 60 a 125 euros; en su grado medio, de 126 a 310 euros; y en su grado máximo, de 311 a 625 euros.

Las graves con multa, en su grado mínimo, de 626 a 1.250 euros, en su grado medio de 1.251 a 3.125 euros; y en su grado máximo de 3.126 a 6.250 euros.

Las muy graves con multa, en su grado mínimo, de 6.251 a 25.000 euros; en su grado medio de 25.001 a 100.005 euros; y en su grado máximo de 100.006 euros a 187.515 euros.

\subsection{Prevención de riesgos laborales}

Corresponde a la Inspección de Trabajo y Seguridad Social la vigilancia y exigencia del cumplimiento de las normas legales, reglamentarias y contenido normativo de los convenios colectivos en el ámbito de prevención de riesgos laborales.

Según reza el artículo 1 de la Ley 31/1995, de 8 de noviembre, de Prevención de Riesgos Laborales (BOE 10/11/1995) (LPRL), la normativa sobre prevención de riesgos laborales está constituida por la presente Ley, sus disposiciones de desarrollo o complementarias y cuantas otras normas, legales o convencionales, contengan prescripciones relativas a la adopción de medidas preventivas en el ámbito laboral o susceptibles de producirlas en dicho ámbito. 
La LPRL tiene por objeto promover la seguridad y la salud de los trabajadores mediante la aplicación de medidas y el desarrollo de las actividades necesarias para la prevención de riesgos derivados del trabajo. A tales efectos, establece los principios generales relativos a la prevención de los riesgos profesionales para la protección de la seguridad y de la salud, la eliminación o disminución de los riesgos derivados del trabajo, la información, la consulta, la participación equilibrada y la formación de los trabajadores en materia preventiva, en los términos señalados en la misma.

El artículo 14 reconoce el derecho de los trabajadores a una protección eficaz en materia de seguridad y salud en el trabajo y el correlativo deber del empresario de protección de los trabajadores frente a los riesgos laborales, que se concreta en el cumplimiento de obligaciones relativas al establecimiento de una organización preventiva, evaluación de riesgos y planificación de medidas preventivas, información y formación de los trabajadores en materia de prevención de riesgos laborales, fomentar la consulta y participación de los trabajadores y sus representantes en materia de prevención de riesgos laborales, garantizar la vigilancia de la salud de los trabajadores así como garantizar condiciones materiales de trabajo adecuadas.

El artículo 3 de la LPRL, en su apartado 4, excluye de su ámbito de aplicación a la relación laboral de carácter especial del servicio del hogar familiar. Señala el precepto que no obstante lo anterior, el titular del hogar familiar está obligado a cuidar de que el trabajo de sus empleados se realice en las debidas condiciones de seguridad e higiene.

Por su parte, el Real Decreto 1620/2011 señala en el artículo 7, referido a los derechos y deberes, que el empleador está obligado a cuidar de que el trabajo del empleado de hogar se realice en las debidas condiciones de seguridad y salud, para lo cual adoptará medidas eficaces, teniendo debidamente en cuenta las características específicas del trabajo doméstico.

Además, el apartado primero del artículo 7 indica que el trabajador tendrá los derechos previstos en el artículo 4 del Estatuto de los Trabajadores, entre los que se encuentra el derecho a la integridad física y a una adecuada política de Seguridad e Higiene.

Por tanto, resulta claro que en la relación laboral del hogar familiar el trabajador tiene derecho a la integridad física y el empleador un correlativo deber de velar porque el trabajo se realice en las debidas condiciones de seguridad y salud, pero esta obligación no se concreta en el cumplimiento de las obligaciones previstas en la LPRL o en el respeto de unas mínimas condiciones materiales de seguridad previstas en su normativa de desarrollo.

La vigilancia del mantenimiento de unas condiciones de seguridad y salud adecuadas que corresponde a la Inspección de Trabajo presenta así varias dificultades:

La primera, la concreción del concepto indeterminado de condiciones de seguridad y salud adecuadas, al no resultar aplicable ni la Ley de Prevención de Riesgos Laborales, 
ni su normativa de desarrollo, ni las normas jurídico técnicas cuyo carácter vinculante viene dado por aquélla.

La segunda, la comprobación de las condiciones de seguridad y salud, que requiere observación directa de una prestación de servicios que se desarrolla en un domicilio particular, con los condicionantes que esto supone y que ya han sido expuestos más arriba.

En tercer lugar, las consecuencias derivadas del incumplimiento. El artículo 5 del TRLISOS señala que son infracciones laborales en materia de prevención de riesgos laborales las acciones u omisiones de los diferentes sujetos responsables que incumplan las normas legales, reglamentarias y cláusulas normativas de los convenios colectivos en materia de seguridad y salud en el trabajo sujetas a responsabilidad conforme a esta ley.

Las infracciones se tipifican en el artículo 11 del TRLISOS las leves, en el artículo 12 las graves y en el artículo 13 las muy graves. Todas ellas describen como infracciones las vulneraciones de las obligaciones previstas en la Ley de Prevención de Riesgos Laborales y sus normas de desarrollo, por lo que no podrá incurrir en ellas el empleador en el ámbito del hogar familiar que no está vinculado por esta normativa.

Esto no significa que la obligación del empleador de garantizar medidas eficaces para que el trabajo se realice en condiciones adecuadas de seguridad y salud sea una obligación vacía de contenido y carente de eficacia.

El propio artículo 7 del Real Decreto 1620/2011 prevé que “el incumplimiento grave de estas obligaciones será justa causa de dimisión del empleado”.

Por otro lado, el artículo 7.10 del Texto Refundido de la Ley de Infracciones y Sanciones en el Orden Social considera infracción grave en materia laboral los actos u omisiones que fueren contrarios a los derechos de los trabajadores reconocidos en el artículo 4 de la Ley del Estatuto de los Trabajadores. En la medida en que el derecho a la integridad física, contemplado en el artículo 4.2.d) del Real Decreto Legislativo 2/2015, de 23 de octubre, por el que se aprueba el texto refundido de la Ley del Estatuto de los Trabajadores (BOE 24/10/2015), es un derecho reconocido al empleado de hogar, su incumplimiento podría ser constitutivo de esta infracción.

Especial atención merece el supuesto de accidente de trabajo o enfermedad profesional del empleado de hogar. El artículo 23.3 de la LPRL señala que "El empresario estará obligado a notificar por escrito a la autoridad laboral los daños para la salud de los trabajadores a su servicio que se hubieran producido con motivo del desarrollo de su trabajo, conforme al procedimiento que se determine reglamentariamente.”

En cuanto a los accidentes de trabajo, el procedimiento reglamentario de notificación es el previsto en la Orden TAS/2926/2002, de 19 de noviembre (BOE 21/11/2002), por la que se establecen nuevos modelos para la notificación de los accidentes de trabajo y se 
posibilita su transmisión por procedimiento electrónico, sustituyendo a los modelos establecidos en la Orden de 16 de diciembre de 1987 que sigue vigente en cuanto a las instrucciones para su cumplimentación y tramitación.

El artículo 3 de la Orden de 16 de diciembre de 1987 por la que se establecen nuevos modelos para la notificación de accidentes de trabajo y se dan instrucciones para su cumplimentación y tramitación (BOE 29/12/1987) establece que "El parte de accidente de trabajo deberá cumplimentarse en aquellos accidentes de trabajo o recaídas que conlleven la ausencia del accidentado del lugar de trabajo de, al menos, un día salvedad hecha del día en que ocurrió el accidente-, previa baja médica.

Dicho documento será remitido por el empresario o trabajador por cuenta propia, según proceda, de acuerdo con lo establecido en el apartado 2 de la presente Orden, a la Entidad gestora o colaboradora que tenga a su cargo la protección por accidente de trabajo, en el plazo máximo de cinco días hábiles, contados desde la fecha en que se produjo el accidente o desde la fecha de la baja médica.”

El artículo 2 establece que "1. El empresario cumplimentará, según los casos, el parte de accidente de trabajo y la relación de accidentes de trabajo ocurridos sin baja médica en los modelos oficiales (...)”

Los destinatarios del parte de accidente de trabajo son, entre otros la entidad gestora o colaboradora y la autoridad laboral.

En relación con las enfermedades profesionales, el Real Decreto 1299/2006, de 10 de noviembre, por el que se aprueba el cuadro de enfermedades profesionales en el sistema de la Seguridad Social y se establecen criterios para su notificación y registro (BOE 19/12/2006), establece en su artículo 4 que “en caso de enfermedad profesional, y sin perjuicio de las obligaciones empresariales derivadas del artículo 23 de la Ley 31/1995, de 8 de noviembre, de Prevención de Riesgos Laborales, la entidad gestora o colaboradora que asuma la protección de las contingencias profesionales elaborará y tramitará el parte de enfermedad profesional correspondiente, en los términos que establezcan las disposiciones de aplicación y desarrollo. La empresa deberá facilitar a la entidad gestora o colaboradora la información que obre en su poder y que sea requerida para la elaboración del parte indicado en el apartado anterior."

En desarrollo de este precepto se aprueba la Orden TAS/1/2007, de 2 de enero, por la que se establece el modelo de parte de enfermedad profesional, se dictan normas para su elaboración y transmisión y se crea el correspondiente fichero de datos personales (BOE 04/01/2007), que prevé en su Disposición adicional segunda la posibilidad de considerar el parte electrónico de enfermedad profesional como comunicación formal a la autoridad laboral de la misma: "El parte electrónico de enfermedad profesional que se regula en esta orden podrá ser considerado como notificación formal por el empresario a la autoridad laboral competente cuando ésta así lo estime. “ 
Por tanto, la cumplimentación del parte de accidente de trabajo según lo previsto en la Orden de 16 de diciembre de 1987 y en los modelos oficiales establecidos en la Orden TAS/2926/2002, de 19 de noviembre, y el parte electrónico de enfermedad profesional previsto Orden TAS/1/2007, de 2 de enero , constituye la forma de dar cumplimiento a la obligación prevista en el artículo 23.3 de la Ley de Prevención de Riesgos Laborales de notificar a la autoridad laboral los daños para la salud de los trabajadores.

El incumplimiento de esta obligación está tipificado como infracción en materia de prevención de riesgos laborales, calificada como leve en el artículo 11.2 y consistente en no dar cuenta, en tiempo y forma, a la autoridad laboral competente, conforme a las disposiciones vigentes, de los accidentes de trabajo ocurridos y de las enfermedades profesionales declaradas cuando tengan la calificación de leves o calificada como grave en el artículo 12.3 en caso de que los accidentes de trabajo ocurridos y de las enfermedades profesionales que tengan la calificación de graves, muy graves o mortales.

Aunque la obligación prevista en el artículo 23.3 de la Ley de Prevención de Riesgos Laborales no alcanzaría al titular del hogar familiar, por estar esta relación laboral fuera del ámbito de aplicación de la norma, si estaría obligado a cumplimentar el parte de accidente de trabajo en los términos previstos en la Orden de 16 de diciembre de 1987 y Orden TAS/2926/2002, de 19 de noviembre y a cumplir las obligaciones de información previstas en el Real Decreto 1299/2006, de 10 de noviembre, para la cumplimentación del parte de enfermedad profesional.

La Orden de 16 de diciembre de 1987 ha derogado el artículo 21 de Orden de 13 de octubre de 1967 por la que se establecen normas para la aplicación y desarrollo de la prestación por incapacidad laboral transitoria (incapacidad temporal) en el Régimen General de la Seguridad Social, referido a la notificación de accidentes de trabajo mientras que la Orden TAS/1/2007, de 2 de enero, ha derogado el artículo 22, referido a la notificación de enfermedades profesionales. Por tanto, estas normas se dictan en desarrollo de la normativa de Seguridad Social de la que si resultan obligaciones para el empleador en esta relación laboral.

Resulta dudoso no obstante que, en caso de incumplimiento de la obligación de comunicar los partes de accidente de trabajo o enfermedad profesional el empleador pudiese ser sancionado conforme a los tipos previstos en los artículos 11.2 y 12.3 del Texto Refundido de la Ley de Infracciones y Sanciones en el Orden Social puesto que la conducta que tipifican estos preceptos es no dar cuenta a la autoridad laboral de los accidentes de trabajo y enfermedades profesionales, estableciéndose esta obligación en el artículo 23.3 de la Ley de Prevención de Riesgos Laborales y no en la Orden de 16 de diciembre de 1987 o en el Real Decreto 1299/2006 que sólo establecen los modelos y mecanismos para llevar a cabo la notificación de las situaciones que dan lugar a estas contingencias. 
Pero, en la medida en que la obligación de cumplimentar estos partes no viene determinada exclusivamente por el cumplimiento de la normativa de prevención de riesgos laborales sino en cumplimiento de la normativa referida a las prestaciones de Seguridad Social, el incumplimiento podría constituir una infracción leve en materia de Seguridad Social, tipificada en el artículo 11.4 del TRLISOS y consistente en no facilitar o comunicar fuera de plazo a las entidades correspondientes los datos, certificaciones y declaraciones que estén obligados a proporcionar, u omitirlos, o consignarlos inexactamente.

\subsection{Sistema de la Seguridad Social}

La vigilancia y exigencia del cumplimiento de las normas legales y reglamentarias en materia de Seguridad Social alcanza, según dispone el artículo 12 de la Ley 23/2015, Ordenadora del Sistema de Inspección de Trabajo y Seguridad Social, entre otras normas a las siguientes:

1. ${ }^{\circ}$ Normas en materia de campo de aplicación, inscripción, afiliación, altas y bajas de trabajadores, cotización y recaudación de cuotas del Sistema de la Seguridad Social.

2. ${ }^{\circ}$ Normas sobre obtención y disfrute de las prestaciones del Sistema de la Seguridad Social, incluidas las prestaciones por desempleo y la prestación por cese de actividad.

\subsubsection{Encuadramiento y cotización.}

Corresponde a la Inspección de Trabajo y Seguridad Social vigilar y exigir el cumplimiento de las normas en materia de alta y cotización en el Sistema de Seguridad Social.

Los empleados de hogar se encuadran en el sistema especial de empleados de hogar previsto en el Régimen General de la Seguridad Social tal y como se establece en el artículo 250 del Real Decreto Legislativo 8/2015, de 30 de octubre, por el que se aprueba el Texto Refundido de la Ley General de la Seguridad Social (BOE 31/10/2015).

En caso de que la Inspección de Trabajo y Seguridad Social constatase el incumplimiento de estas obligaciones podría adoptar estas medidas de conformidad con lo previsto en el artículo 22 de la Ley Ordenadora del Sistema de Inspección de Trabajo y Seguridad Social:

En primer lugar, en caso de incumplimiento relativo a la inscripción del empleador en el Sistema de Seguridad Social o la falta de alta del empleado en el sistema especial de empleados de hogar, se promoverán procedimientos para instar a la Tesorería General de la Seguridad Social, la inscripción, alta y/o en su caso, baja de oficio. 
Por otro lado, la Inspección de Trabajo y Seguridad Social podrá efectuar requerimientos de pago por deudas a la Seguridad Social, así como iniciar expedientes liquidatorios por débitos a la Seguridad Social y conceptos de recaudación conjunta o bonificaciones indebidas, mediante la práctica de actas de liquidación.

Procederá la extensión de actas de liquidación en los supuestos de falta de alta y cotización del empleado de hogar en el sistema especial o cuando se constaten diferencias de cotización, ya sea por cotización en cantidades inferiores a las debidas o por la indebida aplicación de bonificaciones.

Así, si se constatase que el empleador abona un salario superior al que ha declarado a la Tesorería General de la Seguridad Social y esto implica la cotización por una base de cotización inferior a la debida, se producirían diferencias susceptibles de exigirse bien mediante requerimiento de ingreso de cuotas o mediante el inicio de un expediente liquidatorio con la extensión de un acta de liquidación.

Si se constatase que el empleador no cumple los requisitos declarados a la Tesorería General de la Seguridad Social para beneficiarse de bonificaciones previstas procedería exigir la devolución de las mismas mediante un requerimiento de ingreso o la extensión de un acta de liquidación.

Además de estas medidas, tendentes a regularizar la situación antijurídica constatada como consecuencia de la actuación de la Inspección de Trabajo y Seguridad Social, se podrá iniciar un procedimiento sancionador mediante la extensión de acta de infracción en el caso de que los incumplimientos estén descritos como infracciones en el TRLISOS.

El artículo 20 del citado Texto Refundido define las infracciones en materia de Seguridad Social como "las acciones y omisiones de los distintos sujetos responsables a que se refiere el artículo 2.2 de la presente Ley, contrarias a las disposiciones legales y reglamentarias que regulan el sistema de la Seguridad Social, tipificadas y sancionadas como tales en la presente Ley.”

Las infracciones en esta materia en las que podría incurrir el titular del hogar familiar, en su calidad de empleador en la relación laboral de empleados de hogar serían las siguientes:

Serían infracciones leves tipificadas en el artículo 21 del TRLISOS:

- No conservar, durante cuatro años, la documentación o los registros o soportes informáticos en que se hayan transmitido los correspondientes datos que acrediten el cumplimiento de las obligaciones en materia de afiliación, altas, bajas o variaciones que, en su caso, se produjeran en relación con dichas materias, así como los documentos de cotización y los recibos justificativos del pago de salarios y del pago delegado de prestaciones. 
- No comunicar en tiempo y forma las bajas de los trabajadores que cesen en el servicio de la empresa, así como las demás variaciones que les afecten (...).

- No facilitar o comunicar fuera de plazo a las entidades correspondientes los datos, certificaciones y declaraciones que estén obligados a proporcionar, u omitirlos, o consignarlos inexactamente.

- No comunicar a la entidad correspondiente cualquier cambio en los documentos de asociación o de adhesión para la cobertura de las contingencias de accidentes de trabajo y enfermedades profesionales, o en su caso, para las contingencias comunes.

- No remitir a la entidad correspondiente las copias de los partes médicos de baja, confirmación de la baja o alta de incapacidad temporal facilitadas por los trabajadores, o su no transmisión por los obligados o acogidos a la utilización del sistema de presentación de tales copias, por medios informáticos, electrónicos o telemáticos.

De conformidad con lo previsto en el artículo 40 estas infracciones se sancionarían en su grado mínimo, con multas de 60 a 125 euros; en su grado medio, de 126 a 310 euros; y en su grado máximo, de 311 a 625 euros.

Las infracciones graves están tipificadas en el artículo 22 del TRLISOS:

- Iniciar su actividad sin haber solicitado su inscripción en la Seguridad Social; no comunicar la apertura y cese de actividad de los centros de trabajo a efectos de su identificación; no comunicar las variaciones de datos u otras obligaciones establecidas legal o reglamentariamente en materia de inscripción de empresas, incluida la sucesión en la titularidad de la misma, e identificación de centros de trabajo (...)

- No solicitar la afiliación inicial o el alta de los trabajadores que ingresen a su servicio, o solicitar la misma, como consecuencia de actuación inspectora, fuera del plazo establecido. A estos efectos se considerará una infracción por cada uno de los trabajadores afectados.

- No ingresar, en la forma y plazos reglamentarios, las cuotas correspondientes que por todos los conceptos recauda la Tesorería General de la Seguridad Social o no efectuar el ingreso en la cuantía debida, habiendo cumplido dentro de plazo las obligaciones establecidas en los apartados 1 y 2 del artículo 26 del texto refundido de la Ley General de la Seguridad Social (actualmente artículo 29)

- No entregar al trabajador en tiempo y forma, cuantos documentos sean precisos para la solicitud y tramitación de cualesquiera prestaciones, incluido el certificado de empresa.

- Obtener o disfrutar indebidamente cualquier tipo de reducciones, bonificaciones o incentivos en relación con el importe de las cuotas sociales que corresponda. 
- La solicitud de afiliación o del alta de los trabajadores que ingresen a su servicio fuera del plazo establecido al efecto, cuando no mediare actuación inspectora.

- No proceder dentro del plazo reglamentario al alta y cotización por los salarios de tramitación y por las vacaciones devengadas y no disfrutadas antes de la extinción de la relación laboral.

De conformidad con lo dispuesto en el artículo 40 del TRLISOS estos incumplimientos se sancionarán con multa, en su grado mínimo, de 626 a 1.250 euros, en su grado medio de 1.251 a 3.125 euros; y en su grado máximo de 3.126 a 6.250 euros.

Las infracciones muy graves están tipificadas en el artículo 23.

- Dar ocupación como trabajadores a beneficiarios o solicitantes de pensiones u otras prestaciones periódicas de la Seguridad Social, cuyo disfrute sea incompatible con el trabajo por cuenta ajena, cuando no se les haya dado de alta en la Seguridad Social con carácter previo al inicio de su actividad. En este caso el empresario responderá de las prestaciones indebidamente percibidas por el trabajador.

- No ingresar, en la forma y plazos reglamentarios, las cuotas correspondientes que por todos los conceptos recauda la Tesorería General de la Seguridad Social, no habiendo cumplido dentro de plazo las obligaciones establecidas en los apartados 1 y 2 del artículo 26 del texto refundido de la Ley General de la Seguridad Social.

- Pactar con sus trabajadores de forma individual o colectiva la obligación por parte de ellos de pagar total o parcialmente la prima o parte de cuotas a cargo del empresario, o bien su renuncia a los derechos que les confiere el sistema de la Seguridad Social.

- Efectuar declaraciones o facilitar, comunicar o consignar datos falsos o inexactos, que ocasionen liquidaciones, deducciones o compensaciones fraudulentas en las cuotas a satisfacer a la Seguridad Social, o incentivos relacionados con las mismas.

- Retener indebidamente, no ingresándola dentro de plazo, la parte de cuota de Seguridad Social descontada a sus trabajadores o efectuar descuentos superiores a los legalmente establecidos, no ingresándolos en el plazo reglamentario.

Las infracciones se sancionarán con multa, en su grado mínimo, de 6.251 a 25.000 euros; en su grado medio de 25.001 a 100.005 euros; y en su grado máximo de 100.006 euros a 187.515 euros.

No obstante, la infracción grave prevista en el artículo 22.3. consistente en no ingresar, en la forma y plazos reglamentarios, las cuotas correspondientes que por todos los conceptos recauda la Tesorería General de la Seguridad Social o no efectuar el ingreso en la cuantía debida, la infracción muy grave del artículo 23.1.b) consistente en no ingresar, en la forma y plazos reglamentarios, las cuotas correspondientes que por todos los conceptos recauda la Tesorería General de la Seguridad Social y la prevista en el 
artículo 23.1.k) consistente en retener indebidamente, no ingresándola dentro de plazo, la parte de cuota de Seguridad Social descontada a sus trabajadores o efectuar descuentos superiores a los legalmente establecidos, no ingresándolos en el plazo reglamentario se sancionarán con una multa consistente en unos determinados porcentajes de las cuantías dejadas de ingresar o indebidamente retenidas a los trabajadores.

Por otro lado, las infracciones que implican falta de alta de los trabajadores en el sistema de Seguridad Social, se sancionan con multas de cuantía superior.

La infracción prevista en el artículo 22.2, consistente en no solicitar la afiliación inicial o el alta de los trabajadores que ingresen a su servicio, o solicitar la misma, como consecuencia de actuación inspectora, fuera del plazo establecido, se sancionará con la multa siguiente: en su grado mínimo, de 3.126 a 6.250 euros; en su grado medio, de 6.251 a 8.000 euros y, en su grado máximo, de 8.001 a 10.000 euros.

La infracción muy grave tipificada en el artículo 23.1.a) consistente en Dar ocupación como trabajadores a beneficiarios o solicitantes de pensiones u otras prestaciones periódicas de la Seguridad Social, cuyo disfrute sea incompatible con el trabajo por cuenta ajena, cuando no se les haya dado de alta en la Seguridad Social con carácter previo al inicio de su actividad se sancionará con la multa siguiente: en su grado mínimo, de 10.001 a 25.000 euros; en su grado medio, de 25.001 a 100.005 euros y, en su grado máximo, de 100.006 a 187.515 euros.

Además, cuando con ocasión de una misma actuación de inspección se detecten varias infracciones tipificadas en estos preceptos, la sanción que se proponga para cada una de ellas se incrementará:

- Un 20\% en cada infracción cuando se trate de dos trabajadores, beneficiarios o solicitantes.

- Un 30\% en cada infracción cuando se trate de tres trabajadores, beneficiarios o solicitantes.

- Un 40\% en cada infracción cuando se trate de cuatro trabajadores, beneficiarios o solicitantes.

- Un 50\% en cada infracción cuando se trate de cinco o más trabajadores, beneficiarios o solicitantes.

En estos casos. también proceden las sanciones accesorias previstas en el artículo 46 del TRLISOS

A.- Perderán, automáticamente, y de forma proporcional al número de trabajadores afectados por la infracción, las ayudas, bonificaciones y, en general, los beneficios 
derivados de la aplicación de los programas de empleo o formación profesional para el empleo, con efectos desde la fecha en que se cometió la infracción.

La pérdida de estas ayudas, subvenciones, bonificaciones y beneficios derivados de la aplicación de los programas de empleo o formación profesional para el empleo afectará a los de mayor cuantía, con preferencia sobre los que la tuvieren menor en el momento de la comisión de la infracción. Este criterio ha de constar necesariamente en el acta de infracción, de forma motivada.

B.- Podrán ser excluidos del acceso a tales ayudas, subvenciones, bonificaciones y beneficios por un período máximo de dos años (un año en caso de la infracción grave del artículo 22.2), con efectos desde la fecha de la resolución que imponga la sanción.

No obstante, el disfrute de ayudas, subvenciones, bonificaciones y beneficios derivados de la aplicación de programas de empleo o de formación profesional para el empleo está vinculado al ejercicio de una actividad empresarial, circunstancia que no concurre en el titular del hogar familiar que contrata a un empleado de hogar.

Podría plantearse el hecho de que el titular del hogar familiar fuese empleador y contratase a un empleado de hogar encuadrado en la relación laboral especial y, además, realizase una actividad empresarial contratando trabajadores por cuenta ajena y disfrutando, como consecuencia de esta actividad, de ayudas, subvenciones, bonificaciones y beneficios. En caso de incurrir en infracción tipificada en el artículo 22.2 por falta de alta del empleado de hogar cabe preguntarse si procedería la pérdida de alguna subvención, bonificación o beneficio del que viniera disfrutando.

En caso de que la actividad empresarial se realice mediante una entidad mercantil de la que el titular del hogar familiar es socio o partícipe la respuesta no ofrecería duda, puesto que el sujeto beneficiario de la ayuda, subvención o bonificación sería esta entidad y el sujeto responsable de la comisión de la infracción del artículo 22.2 sería el empleador, por lo que no procedería aplicarle la sanción accesoria prevista.

Parece razonable pensar que la misma respuesta procedería en caso de que el titular del hogar familiar fuese además empresario, persona física, puesto que estamos ante relaciones jurídicas diferentes. Por un lado, la creada en su condición de empleador titular del hogar familiar y por otro lado las creadas como empresario que contrata trabajadores por cuenta ajena en ejercicio de una actividad empresarial.

La confusión de ambas situaciones está prevista en el artículo 2.3 del Real Decreto 1620/2011, que establece que "Se presumirá la existencia de una única relación laboral de carácter común y, por tanto, no incluida en el ámbito de esta relación laboral de carácter especial, la relación del titular de un hogar familiar con un trabajador que, además de prestar servicios domésticos en aquél, deba realizar, con cualquier periodicidad, otros servicios ajenos al hogar familiar en actividades o empresas de cualquier carácter del empleador. Dicha presunción se entenderá salvo prueba en 
contrario mediante la que se acredite que la realización de estos servicios no domésticos tiene un carácter marginal o esporádico con respecto al servicio puramente doméstico.”

En este caso, se prevé la unificación de la figura de titular del hogar familiar con la de empresario, pero con carácter excepcional, para el supuesto de prestación de servicios por un mismo trabajador para una misma persona en sus dos dimensiones de titular del hogar familiar y empresario, dando primacía a la relación laboral común.

\subsubsection{Fraude en acceso a prestaciones}

La Inspección de Trabajo y Seguridad Social tiene encomendada la vigilancia del cumplimiento de las normas referidas al acceso a prestaciones de Seguridad Social y le corresponde sancionar los incumplimientos que consisten en actuaciones realizadas por el empleador, por el trabajador o por ambos en connivencia que determinan la obtención indebida de prestaciones del Sistema de Seguridad Social o en cuantías superiores a las debidas.

En estos casos, pueden incurrir en infracciones el empleador, el trabajador o ambos.

Constituyen infracciones muy graves cometidas por el empleador las siguientes, previstas en el artículo 23 del TRLISOS:

- El falseamiento de documentos para que los trabajadores obtengan o disfruten fraudulentamente prestaciones, así como la connivencia con sus trabajadores o con los demás beneficiarios para la obtención de prestaciones indebidas o superiores a las que procedan en cada caso, o para eludir el cumplimiento de las obligaciones que a cualquiera de ellos corresponda en materia de prestaciones.

- Incrementar indebidamente la base de cotización del trabajador de forma que provoque un aumento en las prestaciones que procedan, así como la simulación de la contratación laboral para la obtención indebida de prestaciones.

- No facilitar al Organismo público correspondiente, en tiempo y forma, los datos identificativos de titulares de prestaciones sociales económicas, así como, en cuanto determinen o condicionen el derecho a percibirlas, los de los beneficiarios, cónyuges y otros miembros de la unidad familiar, o los de sus importes, clase de las prestaciones y fecha de efectos de su concesión.

Las conductas constitutivas de infracción en que pueden incurrir los trabajadores se tipifican en los artículos 24, 25 y 26 del TRLISOS. Estas conductas se sancionarán con pérdida de las prestaciones durante un determinado período o extinción de la misma.

\subsection{Trabajo de extranjeros.}

Corresponde también a la Inspección de Trabajo y Seguridad Social la vigilancia y exigencia del cumplimiento de normas en materia de trabajo de extranjeros. 
En un sector en el que gran parte de los empleados tienen origen extranjero corresponde a la Inspección de Trabajo vigilar que disponen de a preceptiva autorización para trabajar, en los términos previstos en el artículo 38 de la Ley Orgánica 4/2000, de 11 de enero, sobre derechos y libertades de los extranjeros en España y su integración social, constituyendo su incumplimiento una infracción tipificada en el artículo 54.1d) de la citada norma consistente en la contratación de trabajadores extranjeros sin haber obtenido con carácter previo la correspondiente autorización de residencia y trabajo, incurriéndose en una infracción por cada uno de los trabajadores extranjeros ocupados, siempre que el hecho no constituya delito. Esta conducta será sancionable a propuesta de la Inspección de Trabajo y Seguridad Social mediante la extensión de acta de infracción. 